SCHOOL EFFECTIVENESS and $\mathrm{SCHOOL}$ IMPROVEMENT An international
hounnal of Resesecth,
Policy and Practice

\section{School Effectiveness and School Improvement}

An International Journal of Research, Policy and Practice

\title{
Students' psychological well-being and its multilevel relationship with immigrant background, gender, socioeconomic status, achievement, and class size
}

\section{Fabio Alivernini, Elisa Cavicchiolo, Sara Manganelli, Andrea Chirico \& Fabio Lucidi}

To cite this article: Fabio Alivernini, Elisa Cavicchiolo, Sara Manganelli, Andrea Chirico \& Fabio Lucidi (2020) Students' psychological well-being and its multilevel relationship with immigrant background, gender, socioeconomic status, achievement, and class size, School Effectiveness and School Improvement, 31:2, 172-191, DOI: 10.1080/09243453.2019.1642214

To link to this article: https://doi.org/10.1080/09243453.2019.1642214

2019.

Щ Article views: 351

View Crossmark data ¿
Submit your article to this journal $\sqsubset$
Q View related articles $ᄃ \pi$

Citing articles: 2 View citing articles $ک \pi$ 


\title{
Students' psychological well-being and its multilevel relationship with immigrant background, gender, socioeconomic status, achievement, and class size
}

\author{
Fabio Alivernini (iD) ${ }^{a}$, Elisa Cavicchiolo (D) ${ }^{a}$, Sara Manganelli (iD) ${ }^{a}$, Andrea Chirico (D) ${ }^{b}$ \\ and Fabio Lucidi ${ }^{b}$ \\ ${ }^{a}$ National Institute for the Evaluation of the Education System (INVALSI), Rome, Italy; ${ }^{\text {b Department of }}$ \\ Developmental and Social Psychology, Sapienza University of Rome, Italy
}

\begin{abstract}
School situations trigger affective states that influence students' achievement and well-being. In the present study, we investigated, on the basis of a sample of 26,470 high-school students and 1,472 classrooms, the relationship of individual characteristics (immigrant background, gender, socioeconomic status, and achievement) as well as classroom characteristics (group composition and size) with students' feelings at school. The results showed that females, low achievers, immigrants, and low-SES students are more at risk of psychological distress at school, with gender and achievement being the most important factors. A doubly latent model analysis revealed that whereas individual socioeconomic status and achievement have a positive impact on students' feelings, the effect of the two variables at the classroom level is negative. The impact of immigrant classroom composition seems to be limited to positive affect and dependent on students' immigrant generation. Finally, students in smaller classrooms show more psychological well-being at school.
\end{abstract}

\section{ARTICLE HISTORY}

Received 15 June 2018

Accepted 12 June 2019

\section{KEYWORDS}

Psychological well-being; immigrant background; gender; socioeconomic status; achievement; classroom size

\section{Introduction}

School situations and contexts of study and learning can trigger several affective states, which can include extreme feelings such as intense happiness or hatred. While attitudes imply an evaluation of an object of thought (Bohner \& Dickel, 2011) as in the case of attitudes towards school or attitudes towards a specific subject, affective states do not necessary entail this kind of judgement. The most basic feelings that students experience can be conceptualized in terms of positive and negative affect (Longo, 2015; Russell \& Barrett, 1999), which are considered to be lasting states that continue beyond the fleeting moment when they first appear. Positive affect includes feelings such as happiness, confidence, and tranquillity. In contrast, anger, fear, and sadness are examples of negative affect. Positive and negative affect are considered to be two inversely related, but distinct dimensions (e.g., Larsen, Hershfield, Stastny, \& Hester, 2017; Laurent et al., 1999). Positive affect has been shown to be associated with higher motivation, a more efficient approach 
to time management, and less distractions due to experience-related thoughts (Rüppel, Liersch, \& Walter, 2015; Weber, Wagner, \& Ruch, 2016). While positive feelings appear to increase cognitive performance, negative feelings have usually an opposite effect (Kaplan, Bradley, Luchman, \& Haynes, 2009; Pekrun, Goetz, Titz, \& Perry, 2002). Affective states are also strictly related to psychological well-being. Their combination predicts depression and anxiety (e.g., Clark \& Watson, 1991; Crawford \& Henry, 2004) and, during adolescence, negative affect appears to be specifically associated with externalizing disorders such as antisocial behaviours and drug abuse (Brieant et al., 2018; Roeser, 2001).

In school effectiveness research, it is therefore important to investigate students' affect at school, due to its relationship with motivation and achievement as well as its association with psychological and social well-being, two variables which are valuable outcomes of attending school. In the literature, individual and classroom characteristics are often seen as having an effect on students' feelings. Individual traits such as immigrant background, socioeconomic status, and gender have been shown to influence psychological well-being (e.g., Chen, 2004; Flook, 2011; Oppedal \& Røysamb, 2004), but also the composition and size of the classroom are considered to have a significant impact on how a student feels at school (e.g., Finn, Pannozzo, \& Achilles, 2003; Goodenow, 1993; Rjosk, Richter, Hochweber, Lüdtke, \& Stanat, 2015). The fact that students can neither choose nor modify their personal or classroom characteristics, and the fact that these characteristics could have an impact on their psychological well-being at school, constitutes a problem of equity which merits research (Alivernini, Manganelli, \& Lucidi, 2016). In fact, understanding the magnitude and the patterns of relationships between these characteristics, students' scholastic achievement, and their positive and negative affect at various different levels is relevant in order to better support individuals and groups in their academic success and well-being. Until now, no study has thoroughly investigated these relationships, and the present research is intended to make up for this lack.

In the first part of this study, in order to obtain reliable and meaningful results, we establish the psychometric properties of the measure of positive and negative affect adopted, with a special attention to its invariance and to its content validity in the school context. In the next section, we review the existing literature. Since there are very few studies on the impact of individual and classroom characteristics on positive and negative affect in a school context, we have also considered research on psychological well-being in general and other non-cognitive school outcomes. Finally, we present the general research questions that guided our study, as well as the specific hypothesis that we tested.

\section{Studies relating individual and classroom characteristics with psychological well-being}

\section{Immigrant background}

Due to the importance of the experience of migration and acculturation, various researches have examined the relationship between having an immigration background and psychological well-being (Yoon et al., 2013). In general, some studies have indicated that immigrants are more at risk of suffering from psychological distress (e.g., Oppedal \& Røysamb, 2004), whereas other authors have found equal levels of well-being (e.g., K. Harker, 2001) or inconsistent and inconclusive patterns (Oppedal \& Røysamb, 2004; 
Xu, Bekteshi, \& Tran, 2010). In the school context, there is evidence that immigrant students are more socially isolated in the classroom (Alivernini \& Manganelli, 2016), more subject to negative and mixed attitudes (Cavicchiolo, Alivernini, \& Manganelli, 2016), and more frequently victimized at school (Alivernini, Manganelli, Cavicchiolo, \& Lucidi, 2019; Fu, Land, \& Lamb, 2013; Strohmeier, Kärnä, \& Salmivalli, 2011) than their native peers, and these phenomena are also known to have an influence on their psychological well-being (Rigby, 2000).

Additionally, several studies suggest that there are significant differences in individual school adjustment between first- and second-generation immigrants (Alivernini, Manganelli, et al., 2018; Fuligni \& Yoshikawa, 2004; Pong \& Zeiser, 2012).

As regards classroom composition, no research has specifically focused on positive and negative affect at school, but there is some evidence that a higher percentage of immigrant students within a school is correlated to higher levels of bullying and physical fighting (Walsh et al., 2015).

\section{Gender}

In general, females have higher negative affect scores and lower positive affect scores than males (Clark \& Watson, 1991). Additionally, many studies also indicate that female adolescents show more emotional problems, such as anxiety and depression, and that they selfreport more interpersonal stressors than their male peers (e.g., Chaplin \& Aldao, 2013; Flook, 2011; Hankin et al., 1998; Nolen-Hoeksema, 1991; Silk, Steinberg, \& Morris, 2003; Wade, Cairney, \& Pevalin, 2002). At the same time, there is evidence that females are more motivated as regards studying than males (Alivernini, Manganelli, et al., 2018; Grouzet, Otis, \& Pelletier, 2006); therefore, the school context might change the pattern of gender differences as regards domain-specific positive and negative affect.

As regards the effects of group context, no research has specifically investigated the relationship between classroom gender composition and students' affective states. The existing literature on other non-cognitive outcomes contains some mixed results. On the one hand, some studies found that girls have a higher sense of belonging and feel more socially accepted in single-sex rather than coeducational schools (Brutsaert \& Van Houtte, 2002, 2004), but, on the other hand, the review of Pahlke, Hyde, and Allison (2014) does not bear out this association between gender context and attitudes towards school.

\section{Socioeconomic status}

Several studies have revealed that psychological well-being varies according to the level of socioeconomic status (SES). Young people with a lower SES have a higher probability of experiencing negative emotions (Chen, 2004), a more elevated risk of developing psychosocial stress and lower levels of well-being (Currie et al., 2012). Furthermore, several studies have shown an association between lower SES and depressive symptoms in adolescents (von Rueden, 2006), while higher levels of SES are generally associated with better health (Bradley \& Corwyn, 2002).

As regards classroom composition, there is some evidence suggesting that its socioeconomic level could have an opposite effect to individual socioeconomic levels. In fact, Crosnoe (2009) concluded that students experienced more psychosocial problems in 
schools with a higher proportion of students with a middling to high income or with college-educated parents.

\section{Achievement}

The existing literature has shown that academic achievement and student's positive emotions are positively related (e.g., King, 2015; Seligman, Ernst, Gillham, Reivich, \& Linkins, 2009; Suldo, Thalji, \& Ferron, 2011; Van Petegem, Aelterman, Van Keer, \& Rosseel, 2008).

As regards classroom composition, no studies hitherto have investigated the effect of group achievement on positive and negative affect at school. Studies on other non-cognitive outcomes indicate some mixed results. In their review, Belfi, Goos, De Fraine, and Van Damme (2012) note that research findings relating group ability with school attitudes are inconsistent. However, studies based on the big-fish-little-pond (BFLP) frame of reference model have consistently shown that students who attend classrooms with higher achievements have lower self-concepts (e.g., Marsh \& Hau, 2003; Nagengast \& Marsh, 2012; Thijs, Verkuyten, \& Helmond, 2010).

\section{Classroom size}

Smaller groups of students appear to promote supportiveness and caring about each other. A large number of studies have provided evidence that students in small classes exhibit less antisocial behaviours such as disruptiveness and misbehaving (for a review, see Finn et al., 2003). There is also some evidence that small classes promote prosocial behaviours such as collaborating with other students (e.g., Finn, Forden, Verdinelli, \& Pannozzo, 2001). Since positive social interactions in class appear to be related to well-being (Layous, Nelson, Oberle, Schonert-Reichl, \& Lyubomirsky, 2012), it can be expected that smaller classes should have a positive impact on students' feelings at school.

\section{Research questions and hypotheses}

The literature we reviewed suggests that there could be a relationship between students' feelings at school and individual and classroom characteristics. However, previous research has provided rather mixed results and no conclusive evidence regarding psychological well-being at school. In order to address these shortcomings, the present study intended to address the following research questions:

- R1 What individual characteristics (immigration backgrounds, gender, socioeconomic status, prior achievement) tend to be more closely associated with students' positive and negative affective states at school?

- R2 What classroom characteristics (compositional variables and size) tend to be more closely associated with students' positive and negative affective states at school?

- R3 Are the classroom compositional effects in the same direction of corresponding effects at the student level?

This last research question is related to the fact that compositional effects can be either positive or negative. Positive compositional effects of a group-level variable go in the same direction as the corresponding individual variable. This is usually the case, for example, for 
the consequences of grouping together students with high socioeconomic status on individual achievement (Van Ewijk \& Sleegers, 2010). In contrast, when a compositional effect is negative, the effects of the group-level variable and the individual-level variable are opposite to each other (Harker \& Tymms, 2004). The best documented case of such a pattern is the big-fish-little-pond effect, which points to a positive correlation between achievement and self-concept at the individual level, as well as a contrary relationship at the group level (e.g., Marsh, 2007; Marsh \& Craven, 2002; Marsh \& Hau, 2003; Marsh et al., 2008).

The current study also tested two specific hypotheses based on the reviewed literature.

(1) Achievement and socioeconomic status will have a positive effect on students' feelings at the individual level, but a negative and paradoxical compositional effect at the group level.

This hypothesis is based on the idea that socioeconomic status, not only achievement, can provoke the processes of comparison at the basis of the big-fish-little-pond effect (Crosnoe, 2009). Since intragroup comparisons relating to status have been shown to have an emotional impact (Zell \& Alicke, 2009), we expected a negative effect of both socioeconomic classroom contexts and achievement on students' feelings at school.

(2) There is a negative relationship between classroom size and students' feelings at school.

This effect can be expected on the basis of the literature, which indicates that small groups promote supportiveness among their members (Finn et al., 2003), which is usually related to phenomena of psychological well-being (Rigby \& Slee, 1993).

\section{Sample and procedures}

The data analysed in our study came from a sample of 26,470 Italian 10th-grade students in 1,472 classrooms (781 schools) who took part in a national survey held in 2015 . In accordance with the sample design adopted by the Italian National Institute for the Evaluation of the Education System (INVALSI, 2011), participating students were sampled from the whole population of Italian upper secondary schools and were a nationally representative sample of 10th-grade students. One or two classes of 10th graders were randomly selected from each school, and all the students in each of these classes were assessed in the survey. Each school dealt with the process of informed consent and parental permission according to a National assessment protocol (National Institute for the Evaluation of the Education System, 2015a). Students were also given a standardized introduction to the survey, which informed them of its purpose and gave them instructions on how to complete the questionnaire. All the participating students completed the anonymous questionnaires in class during the first part of an ordinary school day.

The average age of the students was 15.6 years $(S D=.76)$ with a slight prevalence of females (Females: 50.9\%; Males: 49.1\%); 6.7\% of the students were first-generation immigrants, while $5.7 \%$ were second-generation immigrants. The average classroom size was 22.6 students. The data that corroborate the findings of the present study are available at: https://invalsi-serviziostatistico.cineca.it/. 


\section{Measures}

\section{Feelings At School Scale (FASS)}

According to several authors (Tian, Wang, \& Huebner, 2015; Whitley, Huebner, Hills, \& Valois, 2012), domain-specific measures of well-being are better indicators of adaptive functioning in children and adolescents than general scales. Unfortunately, at the present time there is a lack of time-efficient psychometrically sound measures for assessing adolescents' positive and negative affect, with specific reference to a school context. ${ }^{1}$ Therefore, for the present large-scale study, we developed a short instrument measuring positive and negative affect specific to the school domain, the Feelings At School Scale (FASS). This was done on the basis of a secondary analysis of the qualitative data of a study intended to explore emotional states and motivations self-reported by students when they are at school (Alivernini, Lucidi, \& Manganelli, 2008). Secondary school students in the qualitative study $(N=606)$ were asked a series of open-ended questions, one of which was "Describe how you have felt at school over the last few weeks". A statistical textual analysis was performed on the students' free answers, and two independent evaluators selected the four most frequent words related to positive affect and the four most frequent words related to negative affect. The task was easy (counting the frequency of single words in a list), and the results were the same for the two evaluators. In order to compare the emotional labels obtained with those of the Positive and Negative Affect Schedule for Children (PANAS-C) (Laurent et al., 1999), a widespread 30-item nondomain-specific measure of adolescents' affect, the words that we had selected were translated into English by a native English speaker. For positive affect, these words were: happy/cheerful/good/calm. For negative affect, they were: angry/upset/worried/sad. With the exception of one item for positive affect (good) and one for negative affect (worried), all the content of the remaining six items of the FASS also occurred in the widespread PANAS-C emotional labels. The FASS therefore appears to be a scale with good content validity in the school context, since it is based on items frequently used in the assessment of positive and negative affect, as well as on emotional states frequently reported by students themselves. The final version of the FASS (see Appendix 1) includes four items for positive affect and four items for negative affect. Students are asked to indicate how often they have experienced at school feelings described in each item over the past few months using a 5-point scale ranging from 1 (never) to 5 (very often). In the first part of the results section, the psychometric properties of the FASS are described in detail.

\section{Gender and immigrant background}

Gender was coded as $0 / 1$, with 1 indicating males and 0 indicating females. Student's immigrant background was determined in accordance with the definitions of the Organisation for Economic Co-operation and Development (OECD, 2014). Students born in Italy with parents who were born in another country were thus considered second-generation immigrants, while those who were foreign born and with foreign-born parents were defined as first-generation immigrants. Finally, native students were considered to be those who were born in Italy, or with at least one parent born in Italy; or those who were born in another country, but with at least one parent born in Italy. Immigrant 
background was coded by means of two dummy variables $(0 / 1)$, one for the first generation and one for the second generation, with native students serving as the reference category.

\section{Socioeconomic status}

Socioeconomic status (SES) was considered as a composite variable computed on the basis of four different indicators related to students' family background and consistent with the OECD PISA (Programme for International Student Assessment) international survey (OECD, 2014). The indicators were: educational level of parents; occupational level of parents (e.g., small business owner, clerk); home possessions (e.g., personal computer, a desk for doing homework); and home literacy resources (number of books students had in their homes). Socioeconomic status was a standardized variable derived from the four indicators via principal component analysis (PCA) with mean 0 and standard deviation 1 in the general population of students.

\section{Prior achievement}

The variable of "prior achievement" was based on the mark that students had obtained in the national state examination that students take at the end of the first cycle of education in Italy (Grade 8) and that they have to pass in order to be allowed access to the second cycle of education (high school). In the year that the present study was conducted, the state examination included four written tests (in Italian, mathematics, and two foreign languages), as well as an oral examination on all subjects. The state examination also included standardized tests elaborated by the National Institute for the Evaluation of the Education System (INVALSI) that covered reading comprehension in Italian (49 items) and reasoning skills and mathematical skills (37 items), with items presented mainly as multiple-choice and short-answer questions. Standardized test properties were evaluated by means of Rasch Analysis (National Institute for the Evaluation of the Education System, 2015b). The final pass mark for the state examination was expressed as a whole number from 6 to 11 (with 11 indicating 10 with honours).

\section{Classroom size}

Classroom size was determined as the total number of students attending classes in the school year in which the test was administered according to a school's official documentation. Information about the sizes of classes was provided by the schools, and the total number of students that they communicated also included those students who, for whatever reason, did not participate in the present study.

\section{Data analysis}

The software Mplus (Version 8; Muthén \& Muthén, 1998-2017) was used for all the analyses. First, in order to investigate the psychometric properties of the Feelings At School Scale, the posited measurement model with two correlated factors (i.e., positive affect and negative affect) and a one-factor solution were estimated using a robust maximum 
likelihood estimation method. This allowed us to take into consideration the hierarchical structure of the data (students nested within classes) and to compute correct estimates and test statistics. The model fit was assessed using maximum likelihood robust (MLR) chi-square test statistic and multiple fit indices (comparative fit index [CFI], root mean square error of approximation [RMSEA], standardized root mean square residual [SRMR]). We considered the most commonly used references for establishing the cut-off values for well-fitting models (Hu \& Bentler, 1999; Loewenthal, 2001). We examined the measurement invariance of the positive affect (PA) and negative affect (NA) scales across gender (male or female) and immigrant background (native, first, or second generation) by means of a hierarchical series of multigroup confirmatory factor analyses. We imposed increasingly restrictive equality constraints on the model's parameters, and we examined for each variable the configural, metric, and scalar invariance. Due to the large sample size, in each step we compared the change in $C F I$ values $(\triangle C F I \leq .01)$ to test the invariance for the measurement model (Cheung \& Rensvold, 2002).

Subsequently, a multilevel structural equation model specified on the basis of our research questions and hypotheses was tested. Categorical variables at the student level (Male, First-generation immigrant, Second-generation immigrant) were not centred. Quantitative variables at the student level (SES, Prior achievement) were centred at their grand mean. Therefore, the estimates of background students' variable aggregated at the classroom level were interpretable as compositional effects (Raudenbush \& Bryk, 2002). Positive and negative affect were analysed using a doubly latent approach with cross-level measurement invariance (e.g., Lüdtke, Marsh, Robitzsch, \& Trautwein, 2011; Marsh et al., 2012). In this approach, constructs are latent in relation to items, and there is a latent aggregation of multiple students' items to form multiple classroom indicators (Televantou et al., 2015). Using latent measurement models at both levels and latent aggregation for the classroom level constructs allowed us to correct for possible measurement as well as sampling errors.

The very small amount of missing data (less than $2 \%$ of the cases) was handled using the full information maximum likelihood method as implemented in Mplus (Muthén \& Muthén, 1998-2017). Due to the complex structure of the student sample, sampling weights were applied to the data (INVALSI, 2015b).

\section{Results}

\section{Psychometric properties of the FASS}

Our results empirically confirmed the hypnotized two-factor structure for PA and NA; all the fit indices indicated a good fit of the model: $C F I=.965 ;$ RMSEA $=.059$; SRMR $=.033$ (Hu \& Bentler, 1999; Schreiber, Nora, Stage, Barlow, \& King, 2006). The one-factor solution fitted the data very poorly $(\mathrm{CFI}=.79$; $\mathrm{RMSEA}=.14$; $\mathrm{SRMR}=.09)$ compared to the posited two-factors model. In the posited model, all the standardized factor loadings were statistically significant $(p<.001)$ and ranged from .555 to .815 , as shown in Table 1. PA and NA are significantly negatively correlated with each other $(-.608 ; p<.001)$. The two scales showed acceptable internal consistency with Cronbach's alpha values of .84 for PA and .72 for NA (Loewenthal, 2001). 
Table 1. Confirmatory factor analysis results for PA and NA scales: factor loadings.

\begin{tabular}{lcc}
\hline \multirow{2}{*}{ Items } & \multicolumn{2}{c}{ Factor loadings } \\
\cline { 2 - 3 } & Positive Affect (PA) & Negative Affect (NA) \\
\hline I felt happy & .815 \\
I felt cheerful & .805 & \\
I felt good & .773 & .753 \\
I felt calm & .644 & .627 \\
I felt sad & & .589 \\
I felt upset & .555 \\
I felt worried & & .555 \\
I felt angry &
\end{tabular}

Regarding measurement invariance across gender, the comparison of the configural invariance model with the metric invariance model (in which all the factor loadings were constrained to be equal across groups) showed that the difference in the CFI between the two models was smaller than the cutoff criterion $(\Delta \mathrm{CFI}=.001)$. The comparison between the metric invariance model with the scalar invariance model (in which all the item intercepts were constrained to be equal across groups) supported the full scalar invariance of the scales $(\triangle \mathrm{CFI}=.014)$. In the multigroup CFA across groups with different immigrant background, the comparison of the configural invariance model with the metric invariance model showed that the difference in the CFI was smaller than the cutoff criterion $(\Delta C F I=.001)$; the comparison between the metric invariance model with the scalar invariance model showed a difference in the CFI within the cutoff criterion $(\Delta \mathrm{CFI}=.002)$.

\section{Multilevel structural equation model results}

The fit for the multilevel factor model of PA and NA with cross-level measurement invariance was good $\left(\mathrm{CFI}=.961 ; \mathrm{RMSEA}=.044 ; \mathrm{SRMR}_{\text {within }}=.034 ; \mathrm{SRMR}_{\text {between }}=.09\right)$. The latent intraclass correlation was .07 both for positive affect and negative affect. The fit of the tested multilevel structural model was also good $(C F I=.95$; $R M S E A=.033$; $\mathrm{SRMR}_{\text {within }}=.028$; $\mathrm{SRMR}_{\text {between }}=.1$ ), and in Figure 1 the effects of the students' individual characteristics at the student level as well as the effects of the variables at the classroom level are presented. In the figure, the correlations between exogenous variables and the measurement model of the outcome variable were omitted to improve readability.

At the student level, the posited model accounted for $2.1 \%$ of the variance in PA $(p<.001)$ and $4.1 \%$ of the variance in NA $(p<.001)$. The tested effects were all statistically significant at least at $p<.05$. Female students had higher levels of NA and slightly lower levels of PA than male students. Higher levels of prior achievement and socioeconomic status predicted higher positive affect scores and lower negative affect scores. Finally, regardless of whether the student was a first- or second-generation immigrant, having an immigration background was related to a slightly lower level of positive affect and a slightly higher level of negative effect.

At the classroom level, the posited model explained $16.4 \%$ of the variance in PA $(p<.001)$ and $37.3 \%$ of the variance in NA $(p<.001)$. Larger classroom group sizes predicted lower levels of positive affect and higher levels of negative affect. Higher group achievement and socioeconomic status were both related to a lower level of positive 


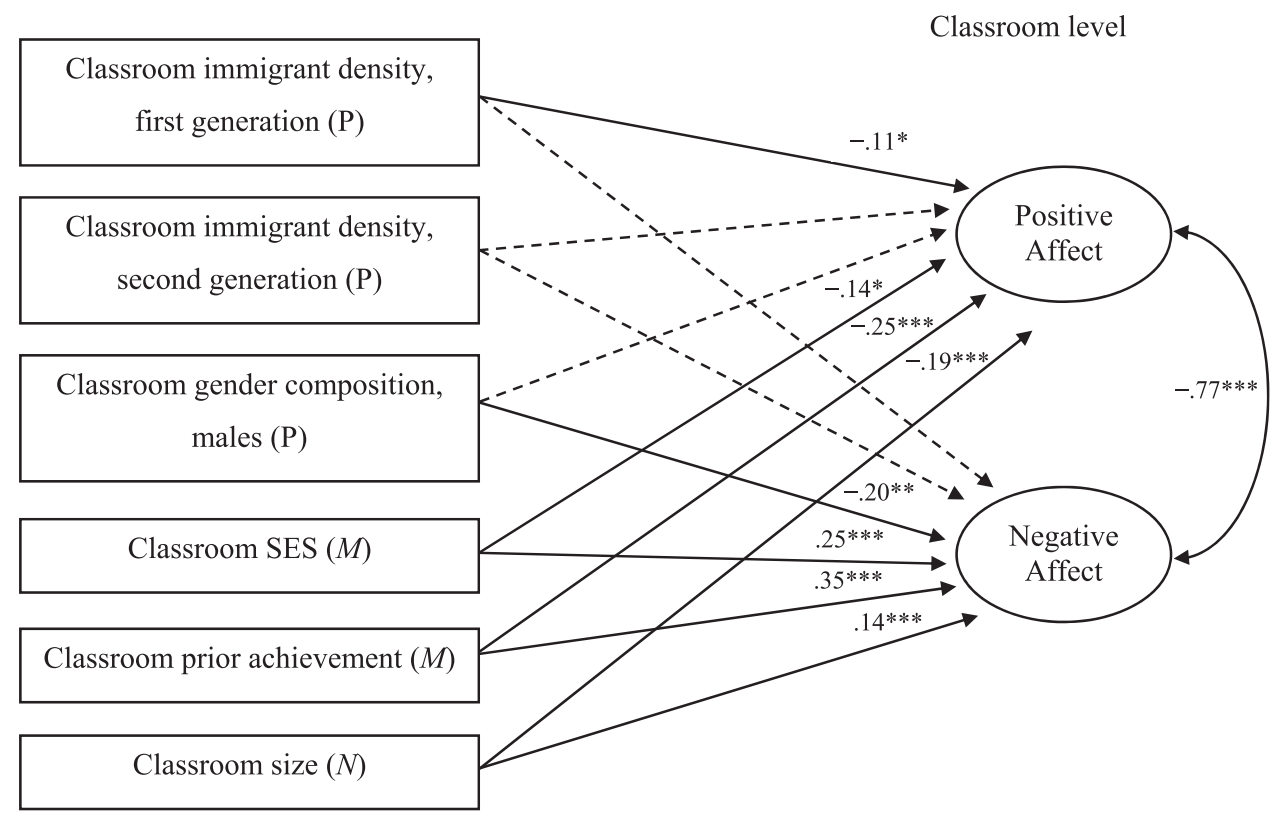

Student level

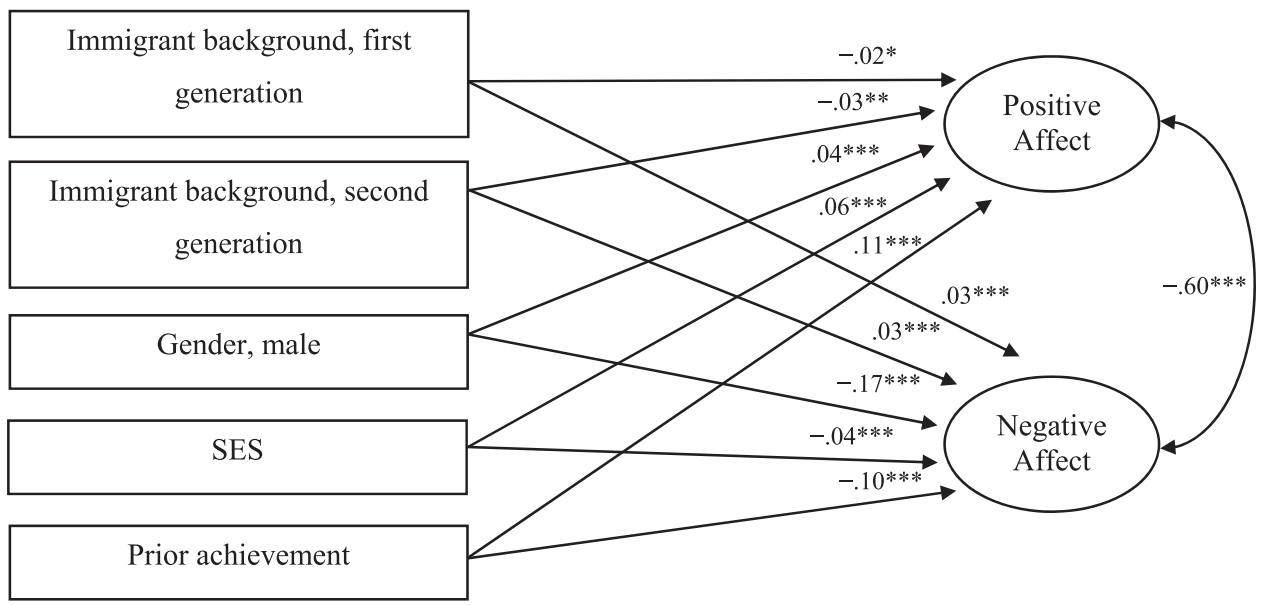

Figure 1. Results of the multilevel structural equation modelling analysis which examined the effects of the students' individual characteristics and the effects of the contextual variables on PA and NA.

Note: The fit indices were $\mathrm{CFI}=.95$; RMSEA $=.033$; $\mathrm{SRMR}_{\text {within }}=.028$; $\mathrm{SRMR}_{\text {between }}=.1$. Parameters estimates are standardised. Dashed lines represent not significant relationships. ${ }^{*} p<.05 .{ }^{* *} p<.01$. ${ }^{* *} p<.001$.

$M=$ mean; $N=$ number; $\mathrm{P}=$ proportion.

affect and a higher level of negative affect. Being in a class at school with a higher percentage of females is related to higher negative affect scores, but it has no impact on positive affect. A higher percentage of first-generation students was associated with lower levels of positive affect, whereas it proved to have no significant relationship as regards negative affect. Finally, the percentage of second-generation students in the classroom did not seem to make any difference to positive or negative affect. 


\section{Discussion}

School situations trigger affective states that can influence the achievement, motivation, and long-term psychological and social well-being of students. In the present study, we investigated the impact of individual characteristics (immigrant background, socioeconomic status, gender, and achievement) as well as classroom characteristics (group composition and size) on students' positive and negative affect at school, on the basis of a random sample of 26,470 students and 1,472 classrooms.

\section{Students' characteristics and students' feelings at school}

Understanding the affective profiles of different groups of students is essential if we wish to encourage and assist their academic achievement and well-being. We have shown that being female or an immigrant, as well as having a low socioeconomic status or a history of low achievement, all have a negative association with students' feelings at school. These results are mostly consistent with the literature on individual differences in general psychological well-being that was reviewed in the introduction. Our study is the first to analyse all these factors at the same time and in the specific context of the school. This allowed us to control for the effects of the various different characteristics and provide some new information on their relative importance in educational settings.

Gender appears to be the most relevant factor. Several studies have indicated that during adolescence girls are more at risk than boys as regards their psychological wellbeing (e.g., Chaplin \& Aldao, 2013; Clark \& Watson, 1991; Flook, 2011), and our results are in line with these findings. We have added to the literature by indicating that, in a school context, this difference is distinguished by a much more noticeable negative affect than a positive affect. On the one hand, this suggests that particular attention should be dedicated towards supporting the psychological well-being of girls at school, since negative affect has been shown to be associated with internalizing and externalizing disorders (e.g., Brieant et al., 2018; Clark \& Watson, 1991; Crawford \& Henry, 2004; Roeser, 2001). On the other hand, the rather negligible lower level of positive affect in females is consistent with the fact that at school girls are usually more motivated than males (Alivernini, Manganelli, et al., 2018; Grouzet et al., 2006). In fact, there is some evidence that positive affective states are more important than negative affective states as regards motivation (Rüppel et al., 2015; Weber et al., 2016). Our results thus appear to have shed some light on the fact that girls can exhibit more psychological distress in addition to being more motivated as regards studying than boys.

The second most important individual factor in explaining students' feelings at school proved to be prior achievement. This result is fully consistent with research findings on the positive relationship between emotions in academic settings and achievement (e.g., Pekrun et al., 2002). Interestingly, it appears that achievement influences positive and negative feelings at school to an equal extent, as it increases the former and correspondingly lowers the latter.

Socioeconomic status proved to be more important than immigrant background as regards affective states at school. It is hardly surprising that belonging to a family with access to many educational, cultural, and economic resources has a positive impact on 
students' feelings in a formal educational context. Nevertheless, our results indicate that this factor has a much smaller emotional effect than that of past academic achievement.

Finally, being an immigrant appears to have a very small impact on psychological wellbeing in the school context. This finding could be helpful in explaining the rather mixed results on this topic in the literature. In fact, similar associations are hard to detect in studies that are not based on large samples.

\section{Classroom characteristics and students' feelings at school}

The two most important compositional variables for explaining differences in affect between classrooms are group achievement before entering high school and group socioeconomic status. It is noteworthy that at the classroom level both these variables have a negative impact on students' psychological well-being, whereas the effect of the corresponding individual variables is positive. This paradoxical pattern is in line with our first hypothesis. Contrast effects of this type have been observed in studies investigating the relationship between group achievement and individual self-concept (e.g., Marsh, 2007; Marsh \& Craven, 2002; Marsh \& Hau, 2003; Marsh et al., 2008). A common explanation for why this happens is based on the frame of reference that groups provide (Kelly, 1952). Being a lower achiever in a high-achiever group means having much higher standards of evaluation than being in the opposite situation, the so-called big fish in a little pond effect (Marsh, 1987). Our data show that, as posited by previous authors (Crosnoe, 2009; Trowbridge, 1970), markers of social worth related to socioeconomic status can be as important as achievement in triggering the processes of comparison that underlie the big-fish-little-pond effect. Our findings also suggest that the set of school outcomes related to the big-fish-little-pond effect might be wider than expected, and that they might include student's positive and negative affective states at school, in addition to students' academic self-concept. This interpretation is consistent with the view that intragroup comparisons related to achievement and status have an emotional impact because they signify directly the standing of the self (Zell \& Alicke, 2009).

Our study also indicates that a higher concentration of females in the classroom is associated with an increase of negative feelings at school. This finding can be explained by the idea of Brutsaert and Van Houtte (2002) that girls are exposed to an affiliationachievement conflict at school, in the sense that they have a gender-oriented need for acceptance by the group, while also having to compete with the group for academic success, and this results in more stress (Belfi et al., 2012). Instead, males' gender-oriented need for rivalry is fully in accordance with their expectations of academic achievement.

The impact of immigrant classroom composition appears to depend on the students' immigrant generation. While a higher proportion of first-generation immigrant students in the classroom is related to less positive feelings, greater numbers of second-generation immigrant students do not appear to have a significant impact. Second-generation students are generally expected to be more socially integrated than first-generation students since they are born in the host country (Alivernini et al., 2019; Barban \& White, 2011; Neidert \& Farley, 1985), and our findings agree with this expectation.

Finally, as expected, we detected a negative relationship between classroom size and positive affect. The idea that smaller classroom groups promote students' psychological well-being is consistent with the literature, which suggests a positive relationship 
between smaller classrooms and prosocial behaviour, which encourages well-being in turn (Layous et al., 2012).

\section{Limitations, strengths, and conclusions of the study}

Our study has some limitations that should be addressed in future research. First, since it was based on a large-scale survey conducted in Italy, the results might not be directly generalizable to other cultural contexts. Second, although prior academic achievement at the level of students (as well as of classrooms) was measured before the beginning of high school and therefore at the very beginning of processes related to group composition, our data did not allow us to closely investigate the development of these processes, and due to its correlational nature does not allow direct causal interpretation. Future research will hopefully identify the mediators of these effects and thereby provide further insight into the current findings, by showing how classroom composition can influence students' affective states. Finally, the adopted sampling strategy allowed us to study students' feelings only at the individual and at the classroom level. Future research should investigate the phenomenon also at the school level and explore possible complex interactions between and within levels (Alivernini \& Manganelli, 2015).

Despite these limitations, we believe that our study has strengths that go beyond the large dimension of the sample of classrooms and students on which it is based. Students' feelings are very important variables in research into school effectiveness, due to their well-documented association with achievement and motivation. Our study is the first to identify and to quantify the possible impact of individual and classroom factors on students' positive and negative affective states at school. Second, as noted by Televantou and colleagues (2015), nearly all the previous research on compositional effects has been based on traditional approaches to multilevel models, which are positively biased, due to the failure to control for measurement error. Our study is one of the few in this field to employ a doubly latent approach (e.g., Marsh et al., 2009), taking measurement error as well as sampling error into account, in order to avoid phantom effects. An additional contribution of the study is that it provides evidence for the validity and the measurement invariance of a short measure of students' positive and negative feelings at school: the FASS, a measure which, due to its time efficiency, is highly suitable for research into educational effectiveness.

Our findings have also implications at several different levels. Teachers working with students in the classroom should consider that, although female students usually have higher levels of performance and motivation at school, they also experience more negative feelings as we showed in the present study. This risk factor is particularly worthy of attention, since negative affect can not only impair processes of learning, but it is also associated with problems of psychosocial development in adolescence (Hanish et al., 2004; Kim, Walden, Harris, Karrass, \& Catron, 2007; Silk et al., 2003). The good news for teachers is that individual socioeconomic status and immigrant background have a relatively small impact on students' affective states, whereas prior achievement increases positive affect and decreases negative affect equally. This means that students are not fated to be either happy or sad at school due to their background or traits they cannot decide or control and that it is possible to take positive actions within the classroom to foster their psychological well-being (Alivernini, Cavicchiolo, Manganelli, Chirico, \& Lucidi, 2018). 
As regards educational policies, it should be noted that small classrooms appear to benefit not only cognitive and behavioural outcomes, as was shown by previous research, but also students' emotional experiences at school. The proportion of immigrant students in a classroom has a limited impact on students' emotions and moods at school, and this small impact appears to be strictly connected to social integration processes. Achievement and socioeconomic status have been shown to be the two most important factors as regards the effects of group composition on psychological well-being at school. All other conditions being equal, students in groups with a higher mean level of achievement and socioeconomic status are less happy than their peers in situations that are less demanding. These results, as well as other factors not entirely of an empirical nature, could be taken into account when considering the issues of group compositions, classroom size, and school outcomes.

\section{Note}

1. Tian and colleagues (2015) proposed single-item measures for measuring adolescents' positive affect and negative affect in the school context.

\section{Disclosure statement}

No potential conflict of interest was reported by the authors.

\section{Notes on contributors}

Fabio Alivernini is a researcher at the Italian National Institute for the Evaluation of the Education System (INVALSI). He completed his Master's degree in Evaluation and PhD at University of Rome "La Sapienza". He has conducted numerous methodological and substantive studies involving the integration of qualitative and quantitative data.

Elisa Cavicchiolo has a PhD in Sociology and Applied Social Science. She works in the area of students' learning assessment at the National Institute for the Evaluation of the Education System (INVALSI) based in Rome, Italy. Her research interests are related to immigration, civic education and citizenship, mixed-method approach, and multilevel analysis.

Sara Manganelli, PhD, is a researcher at the Italian National Institute for the Evaluation of the Education System (INVALSI). She has worked in international comparative surveys on students' academic success and civic engagement, and in national projects about the evaluation of schools. Her major research interests pertain to the analysis of large-scale datasets with multilevel techniques and structural equation modelling.

Andrea Chirico, PhD, is a full-time researcher at "Sapienza" University of Rome, for the psychometric discipline. His research focuses on educational psychology, sport psychology, and psycho-oncology. The Italian Government, the National Cancer Institutes in Italy, and the SHRO in Pennsylvania, USA, have supported Dr Chirico's researches. He is the author of several peer-reviewed publications and book chapters and has also mentored national and international graduate students.

Fabio Lucidi, PhD, is a full professor in Psychometrics at "Sapienza" University of Rome. He has authored more than 130 scientific full papers edited in international scientific journals. He is in the editorial board of different national and international scientific journals. His main focus is the study of people's "self-regulation" of health behaviour. He is involved in different international collaborations with institutions and universities. 


\section{ORCID}

Fabio Alivernini (D) http://orcid.org/0000-0002-8998-9374

Elisa Cavicchiolo (1) http://orcid.org/0000-0001-8552-2737

Sara Manganelli (D) http://orcid.org/0000-0002-1748-7295

Andrea Chirico (D) http://orcid.org/0000-0001-9955-1926

Fabio Lucidi (D) http://orcid.org/0000-0003-2203-9566

\section{References}

Alivernini, F., Cavicchiolo, E., Manganelli, S., Chirico, A., \& Lucidi, F. (2018). Support for autonomy at school predicts immigrant adolescents' psychological well-being. Journal of Immigrant and Minority Health. Advance online publication. doi:10.1007/s10903-018-0839-x

Alivernini, F., Lucidi, F., \& Manganelli, S. (2008). Assessment of academic motivation: A mixed methods study. International Journal of Multiple Research Approaches, 2(1), 71-82. doi:10.5172/ mra.455.2.1.71

Alivernini, F., \& Manganelli, S. (2015). Country, school and students factors associated with extreme levels of science literacy across 25 countries. International Journal of Science Education, 37(12), 1992-2012. doi:10.1080/09500693.2015.1060648

Alivernini, F., \& Manganelli, S. (2016). The classmates social isolation questionnaire (CSIQ): An initial validation. European Journal of Developmental Psychology, 13(2), 264-274. doi:10.1080/17405629. 2016.1152174

Alivernini, F., Manganelli, S., Cavicchiolo, E., Girelli, L., Biasi, V., \& Lucidi, F. (2018). Immigrant background and gender differences in primary students' motivations toward studying. The Journal of Educational Research, 111(5), 603-611. doi:10.1080/00220671.2017.1349073

Alivernini, F., Manganelli, S., Cavicchiolo, E., \& Lucidi, F. (2019). Measuring bullying and victimization among immigrant and native primary school students: Evidence from Italy. Journal of Psychoeducational Assessment, 37(2), 226-238. doi:10.1177/0734282917732890

Alivernini, F., Manganelli, S., \& Lucidi, F. (2016). The last shall be the first: Competencies, equity and the power of resilience in the Italian school system. Learning and Individual Differences, 51, 19-28. doi:10.1016/j.lindif.2016.08.010

Barban, N., \& White, M. J. (2011). Immigrants' children's transition to secondary school in Italy. International Migration Review, 45(3), 702-726. doi:10.1111/j.1747-7379.2011.00863.x

Belfi, B., Goos, M., De Fraine, B., \& Van Damme, J. (2012). The effect of class composition by gender and ability on secondary school students' school well-being and academic self-concept: A literature review. Educational Research Review, 7(1), 62-74. doi:10.1016/j.edurev.2011.09.002

Bohner, G., \& Dickel, N. (2011). Attitudes and attitude change. Annual Review of Psychology, 62, 391417. doi:10.1146/annurev.psych.121208.131609

Bradley, R. H., \& Corwyn, R. F. (2002). Socioeconomic status and child development. Annual Review of Psychology, 53, 371-399. 10.1146/annurev.psych.53.100901.135233

Brieant, A., Holmes, C. J., Maciejewski, D., Lee, J., Deater-Deckard, K., King-Casas, B., \& Kim-Spoon, J. (2018). Positive and negative affect and adolescent adjustment: Moderation effects of prefrontal functioning. Journal of Research on Adolescence, 28(1), 40-55. doi:10.1111/jora.12339

Brutsaert, H., \& Van Houtte, M. (2002). Girls' and boys' sense of belonging in single-sex versus co-educational schools. Research in Education, 68(1), 48-56. doi:10.7227/RIE.68.5

Brutsaert, H., \& Van Houtte, M. (2004). Gender context of schooling and levels of stress among early adolescent pupils. Education and Urban Society, 37(1), 58-73. doi:10.1177/0013124504268070

Cavicchiolo, E., Alivernini, F., \& Manganelli, S. (2016). Immigrants are like ... The representation of immigrants in Italy: The metaphors used by students and their family backgrounds. Journal of Educational, Cultural and Psychological Studies, 13, 161-188. doi:10.7358/ecps-2016-013-cavi

Chaplin, T. M., \& Aldao, A. (2013). Gender differences in emotion expression in children: A meta-analytic review. Psychological Bulletin, 139(4), 735-765. doi:10.1037/a0030737

Chen, E. (2004). Why socioeconomic status affects the health of children: A psychosocial perspective. Current Directions in Psychological Science, 13(3), 112-115. doi:10.1111/j.0963-7214.2004.00286.x 
Cheung, G. W., \& Rensvold, R. B. (2002). Evaluating goodness-of-fit indexes for testing measurement invariance. Structural Equation Modeling: A Multidisciplinary Journal, 9(2), 233-255. doi:10.1207/ S15328007SEM0902_5

Clark, L. A., \& Watson, D. (1991). Tripartite model of anxiety and depression: Psychometric evidence and taxonomic implications. Journal of Abnormal Psychology, 100(3), 316-336. doi:10.1037/0021843X.100.3.316

Crawford, J. R., \& Henry, J. D. (2004). The Positive and Negative Affect Schedule (PANAS): Construct validity, measurement properties and normative data in a large non-clinical sample. British Journal of Clinical Psychology, 43(3), 245-265. doi:10.1348/0144665031752934

Crosnoe, R. (2009). Low-income students and the socioeconomic composition of public high schools. American Sociological Review, 74(5), 709-730. doi:10.1177/000312240907400502

Currie, C., Zanotti, C., Morgan, A., Currie, D., de Looze, M., Roberts, C., ... Barnekow, V. (Eds). (2012). Social determinants of health and well-being among young people. Health Behaviour in Schoolaged Children (HBSC) study: International report from the 2009/2010 survey (Health Policy for Children and Adolescents, No. 6). Copenhagen: WHO Regional Office for Europe. Retrieved from http://www.euro.who.int/_data/assets/pdf_file/0003/163857/Social-determinants-of-healt h-and-well-being-among-young-people.pdf

Finn, J. D., Forden, M. A., Verdinelli, S., \& Pannozzo, G. M. (2001). Evaluation of the class size reduction initiative - Buffalo Public Schools. Buffalo, NY: University at Buffalo, Graduate School of Education.

Finn, J. D., Pannozzo, G. M., \& Achilles, C. M. (2003). The "why's" of class size: Student behavior in small classes. Review of Educational Research, 73(3), 321-368. doi:10.3102/00346543073003321

Flook, L. (2011). Gender differences in adolescents' daily interpersonal events and well-being. Child Development, 82(2), 454-461. doi:10.1111/j.1467-8624.2010.01521.x

Fu, Q., Land, K. C., \& Lamb, V. L. (2013). Bullying victimization, socioeconomic status and behavioral characteristics of 12th graders in the United States, 1989 to 2009: Repetitive trends and persistent risk differentials. Child Indicators Research, 6(1), 1-21. doi:10.1007/s12187-012-9152-8

Fuligni, A. J., \& Yoshikawa, H. (2004). Investments in children among immigrant families. In A. Kalil \& T. DeLeire (Eds.), Monographs in parenting: Family investments in children's potential: Resources and parenting behaviors that promote success (pp. 139-162). Mahwah, NJ: Lawrence Erlbaum

Goodenow, C. (1993). Classroom belonging among early adolescent students: Relationships to motivation and achievement. The Journal of Early Adolescence, 13(1), 21-43. doi:10.1177/ 0272431693013001002

Grouzet, F. M. E., Otis, N., \& Pelletier, L. G. (2006). Longitudinal cross-gender factorial invariance of the Academic Motivation Scale. Structural Equation Modeling: A Multidisciplinary Journal, 13(1), 73-98. doi:10.1207/s15328007sem1301_4

Hanish, L. D., Eisenberg, N., Fabes, R. A., Tracy, L., Ryan, P., \& Schmidt, S. (2004). The expression and regulation of negative emotions: Risk factors for young children's peer victimization. Development and Psychopathology, 16(2), 335-353. doi:10.1017/S0954579404044542

Hankin, B. L., Abramson, L. Y., Moffitt, T. E., Silva, P. A., McGee, R., \& Angell, K. E. (1998). Development of depression from preadolescence to young adulthood: Emerging gender differences in a 10-year longitudinal study. Journal of Abnormal Psychology, 107(1), 128-140. doi:10.1037/0021-843X.107.1.128

Harker, K. (2001). Immigrant generation, assimilation, and adolescent psychological well-being. Social Forces, 79(3), 969-1004. doi:10.1353/sof.2001.0010

Harker, R., \& Tymms, P. (2004). The effects of student composition on school outcomes. School Effectiveness and School Improvement, 15(2), 177-199. doi:10.1076/sesi.15.2.177.30432

Hu, L., \& Bentler, P. M. (1999). Cutoff criteria for fit indexes in covariance structure analysis: Conventional criteria versus new alternatives. Structural Equation Modeling: A Multidisciplinary Journal, 6(1), 1-55. doi:10.1080/10705519909540118

Kaplan, S., Bradley, J. C., Luchman, J. N., \& Haynes, D. (2009). On the role of positive and negative affectivity in job performance: A meta-analytic investigation. Journal of Applied Psychology, 94 (1), 162-176. doi:10.1037/a0013115

Kelly, H. H. (1952). The two functions of reference groups. In G. E. Swanson, T. M. Newcomb, \& E. L. Hartley (Eds.), Readings in social psychology (2nd ed., pp. 410-414). New York, NY: Holt, Rinehart \& Winston. 
Kim, G., Walden, T., Harris, V., Karrass, J., \& Catron, T. (2007). Positive emotion, negative emotion, and emotion control in the externalizing problems of school-aged children. Child Psychiatry and Human Development, 37(3), 221-239. doi:10.1007/s10578-006-0031-8

King, R. B. (2015). Sense of relatedness boosts engagement, achievement, and well-being: A latent growth model study. Contemporary Education Psychology, 42, 26-38. doi:10.1016/j.cedpsych. 2015.04.002

Larsen, J. T., Hershfield, H. E., Stastny, B. J., \& Hester, N. (2017). On the relationship between positive and negative affect: Their correlation and their co-occurrence. Emotion, 17(2), 323-336. doi:10. 1037/emo0000231

Laurent, J., Catanzaro, S. J., Joiner T. E., Jr., Rudolph, K. D., Potter, K. I., Lambert, S., ... Gathright, T. (1999). A measure of positive and negative affect for children: Scale development and initial validation. Psychological Assessment, 11(3), 326-338. doi:10.1037/1040-3590.11.3.326

Layous, K., Nelson, S. K., Oberle, E., Schonert-Reichl, K. A., \& Lyubomirsky, S. (2012). Kindness counts: Prompting prosocial behavior in preadolescents boosts peer acceptance and well-being. PLoS ONE, 7(12): e51380. doi:10.1371/journal.pone.0051380

Loewenthal, K. M. (2001). An introduction to psychological tests and scales (2nd ed.). Hove: Psychology Press.

Longo, Y. (2015). The simple structure of positive affect. Social Indicators Research, 124(1), 183-198. doi:10.1007/s11205-014-0776-6

Lüdtke, O., Marsh, H. W., Robitzsch, A., \& Trautwein, U. (2011). A $2 \times 2$ taxonomy of multilevel latent contextual models: Accuracy-bias trade-offs in full and partial error correction models. Psychological Methods, 16(4), 444-467. doi:10.1037/a0024376

Marsh, H. W. (1987). The big-fish-little-pond effect on academic self-concept. Journal of Educational Psychology, 79(3), 280-295. doi:10.1037//0022-0663.79.3.280

Marsh, H. W. (2007). Self-concept theory, measurement and research into practice: The role of selfconcept in educational psychology (25th Vernon-Wall lecture series). London: British Psychological Society.

Marsh, H. W., \& Craven, R. G. (2002). The pivotal role of frames of reference in academic self-control formation: The "big-fish-little-pond" effect. In F. Pajares \& T. Urdan (Eds.), Adolescence and education: Vol. 2. Academic motivation of adolescents (pp. 83-123). Greenwich, CT: Information Age.

Marsh, H. W., \& Hau, K.-T. (2003). Big-Fish-Little-Pond effect on academic self-concept: A cross-cultural (26-country) test of the negative effects of academically selective schools. American Psychologist, 58(5), 364-376. doi:10.1037/0003-066X.58.5.364

Marsh, H. W., Lüdtke, O., Nagengast, B., Trautwein, U., Morin, A. J. S., Abduljabbar, A. S., \& Köller, O. (2012) Classroom climate and contextual effects: Conceptual and methodological issues in the evaluation of group-level effects. Educational Psychologist, 47(2), 106-124. doi:10.1080/ 00461520.2012 .670488

Marsh, H. W., Lüdtke, O., Robitzsch, A., Trautwein, U., Asparouhov, T., Muthén, B., \& Nagengast, B. (2009). Doubly-latent models of school contextual effects: Integrating multilevel and structural equation approaches to control measurement and sampling error. Multivariate Behavioral Research, 44(6), 764-802. doi:10.1080/00273170903333665

Marsh, H. W., Seaton, M., Trautwein, U., Lüdtke, O., Hau, K. T., O'Mara, A. J., \& Craven, R. G. (2008). The big-fish-little-pond-effect stands up to critical scrutiny: Implications for theory, methodology, and future research. Educational Psychology Review, 20(3), 319-350. doi:10.1007/s10648-008-9075-6

Muthén, L. K., \& Muthén, B. O. (1998-2017). Mplus user's guide (8th ed.). Los Angeles, CA: Authors.

Nagengast, B., \& Marsh, H. W. (2012). Big fish in little ponds aspire more: Mediation and cross-cultural generalizability of school-average ability effects on self-concept and career aspirations in science. Journal of Educational Psychology, 104(4), 1033-1053. doi:10.1037/a0027697

National Institute for the Evaluation of the Education System. (2011). Le rilevazioni degli apprendimenti a.s. 2010-2011 [Evaluation of learning 2010-2011]. Retrieved from https://www.invalsi.it/ esamidistato1011/documenti/Rapporto_SNV\%202010-11_e_Prova_nazionale_2011.pdf

National Institute for the Evaluation of the Education System. (2015a). Rilevazioni nazionali degli apprendimenti 2014-2015 [National evaluation of learning 2014-15]. Retrieved from https:// invalsi-areaprove.cineca.it/docs/attach/035_Rapporto_Prove_INVALSI_2015.pdf 
National Institute for the Evaluation of the Education System. (2015b). Rilevazioni nazionali degli apprendimenti 2014-15 - Rapporto tecnico [National evaluation of learning 2014-15 - Technical report]. Retrieved from http://www.invalsi.it/invalsi/doc_evidenza/2015/024_Rapporto_tecnico_ 2015.pdf

Neidert, L., \& Farley, R. (1985). Assimilation in the United States: An analysis of ethnic and generation differences in status and achievement. American Sociological Review, 50(6), 840-850. doi:10.2307/ 2095507

Nolen-Hoeksema, S. (1991). Responses to depression and their effects on the duration of depressive episodes. Journal of Abnormal Psychology, 100(4), 569-582. doi:10.1037/0021-843X.100.4.569

Oppedal, B., \& Røysamb, E. (2004). Mental health, life stress and social support among young Norwegian adolescents with immigrant and host national background. Scandinavian Journal of Psychology, 45(2), 131-144. doi:10.1111/j.1467-9450.2004.00388.x

Organisation for Economic Co-operation and Development. (2014). PISA 2012 technical report. Retrieved from http://www.oecd.org/pisa/pisaproducts/PISA-2012-technical-report-final.pdf

Pahlke, E., Hyde, J. S., \& Allison, C. M. (2014). The effects of single-sex compared with coeducational schooling on students' performance and attitudes: A meta-analysis. Psychological Bulletin, 140(4), 1042-1072. doi:10.1037/a0035740

Pekrun, R., Goetz, T., Titz, W., \& Perry, R. P. (2002). Academic emotions in students' self-regulated learning and achievement: A program of qualitative and quantitative research. Educational Psychologist, 37(2), 91-105. doi:10.1207/S15326985EP3702_4

Pong, S., \& Zeiser, K. L. (2012). Student engagement, school climate, and academic achievement of immigrants' children. In C. García Coll \& A. K. Marks (Eds.), The immigrant paradox in children and adolescents: Is becoming American a developmental risk? (pp. 209-232). Washington, DC: American Psychological Association.

Raudenbush, S. W., \& Bryk, A. S. (2002). Hierarchical linear models: Applications and data analysis (2nd ed.). Newbury Park, CA: Sage.

Rigby, K. (2000). Effects of peer victimization in schools and perceived social support on adolescent well-being. Journal of Adolescence, 23(1), 57-68. doi:10.1006/jado.1999.0289

Rigby, K., \& Slee, P. T. (1993). Dimensions of interpersonal relation among Australian children and implications for psychological well-being. The Journal of Social Psychology, 133(1), 33-42. doi:10. 1080/00224545.1993.9712116

Rjosk, C., Richter, D., Hochweber, J., Lüdtke, O., \& Stanat, P. (2015). Classroom composition and language minority students' motivation in language lessons. Journal of Educational Psychology, 107(4), 1171-1185. doi:10.1037/edu0000035

Roeser, R. W. (2001). To cultivate the positive ... Introduction to the special issue on schooling and mental health issues. Journal of School Psychology, 39(2), 99-110. doi:10.1016/S00224405 (01)00061-9

Rüppel, F., Liersch, S., \& Walter, U. (2015). The influence of psychological well-being on academic success. Journal of Public Health, 23(1), 15-24. doi:10.1007/s10389-015-0654-y

Russell, J. A., \& Barrett, L. F. (1999). Core affect, prototypical emotional episodes, and other things called emotion: Dissecting the elephant. Journal of Personality and Social Psychology, 76(5), 805819. doi:10.1037/0022-3514.76.5.805

Schreiber, J. B., Nora, A., Stage, F. K., Barlow, E. A., \& King, J. (2006). Reporting structural equation modeling and confirmatory factor analysis results: A review. The Journal of Educational Research, 99(6), 323-337. doi:10.3200/JOER.99.6.323-338

Seligman, M. E. P., Ernst, R. M., Gillham, J., Reivich, K., \& Linkins, M. (2009). Positive education: Positive psychology and classroom interventions. Oxford Review of Education, 35(3), 293-311. doi:10.1080/ 03054980902934563

Silk, J. S., Steinberg, L., \& Morris, A. S. (2003). Adolescents' emotion regulation in daily life: Links to depressive symptoms and problem behavior. Child Development, 74(6), 1869-1880. doi:10.1046/ j.1467-8624.2003.00643.x

Strohmeier, D., Kärnä, A., \& Salmivalli, C. (2011). Intrapersonal and interpersonal risk factors for peer victimization in immigrant youth in Finland. Developmental Psychology, 47(1), 248-258. doi:10. 1037/a0020785 
Suldo, S., Thalji, A., \& Ferron, J. (2011). Longitudinal academic outcomes predicted by early adolescents' subjective well-being, psychopathology, and mental health status yielded from a dual factor model. The Journal of Positive Psychology, 6(1), 17-30. doi:10.1080/17439760.2010. 536774

Televantou, I., Marsh, H. W., Kyriakides, L., Nagengast, B., Fletcher, J., \& Malmberg, L.-E. (2015). Phantom effects in school composition research: Consequences of failure to control biases due to measurement error in traditional multilevel models. School Effectiveness and School Improvement, 26(1), 75-101. doi:10.1080/09243453.2013.871302

Thijs, J., Verkuyten, M., \& Helmond, P. (2010). A further examination of the big-fish-little-pond effect: Perceived position in class, class size, and gender comparisons. Sociology of Education, 83(4), 333-345. doi:10.1177/0038040710383521

Tian, L., Wang, D., \& Huebner, E. S. (2015). Development and validation of the Brief Adolescents' Subjective Well-Being in School Scale (BASWBSS). Social Indicators Research, 120(2), 615-634. doi:10.1007/s11205-014-0603-0

Trowbridge, N. (1970). Effects of socio-economic class on self-concept of children. Psychology in the Schools, 7(3), 304-306. doi:10.1002/1520-6807(197007)7:3<304::AID-PITS2310070321>3.0. $\mathrm{CO} ; 2-\mathrm{X}$

Xu, Q., Bekteshi, V., \& Tran, T. (2010). Family, school, country of birth and adolescents' psychological well-being. Journal of Immigrant \& Refugee Studies, 8(1), 91-110. doi:10.1080/ 15562940903379142

Van Ewijk, R., \& Sleegers, P. (2010). The effect of peer socioeconomic status on student achievement: A meta-analysis. Educational Research Review, 5(2), 134-150. doi:10.1016/j.edurev.2010.02.001

Van Petegem, K., Aelterman, A., Van Keer, H., \& Rosseel, Y. (2008). The influence of student characteristics and interpersonal teacher behaviour in the classroom on student's wellbeing. Social Indicators Research, 85(2), 279-291. doi:10.1007/s11205-007-9093-7

von Rueden, U. (2006). Socioeconomic determinants of health related quality of life in childhood and adolescence: Results from a European study. Journal of Epidemiology \& Community Health, 60(2), 130-135. doi:10.1136/jech.2005.039792

Wade, T. J., Cairney, J., \& Pevalin, D. J. (2002). Emergence of gender differences in depression during adolescence: National panel results from three countries. Journal of the American Academy of Child \& Adolescent Psychiatry, 41(2), 190-198. doi:10.1097/00004583-200202000-00013

Walsh, S. D., Clercq, B., Molcho, M., Harel-Fisch, Y., Davison, C. M., Madsen, K. R., \& Stevens, G. W. J. M. (2015). The relationship between immigrant school composition, classmate support and involvement in physical fighting and bullying among adolescent immigrants and non-immigrants in 11 countries. Journal of Youth and Adolescence, 45(1), 1-16. doi:10.1007/s10964-0150367-0

Weber, M., Wagner, L., \& Ruch, W. (2016). Positive feelings at school: On the relationships between students' character strengths, school-related affect, and school functioning. Journal of Happiness Studies, 17(1), 341-355. doi:10.1007/s10902-014-9597-1

Whitley, A. M., Huebner, E. S., Hills, K. J., \& Valois, R. F. (2012). Can students be too happy in school? The optimal level of school satisfaction. Applied Research in Quality of Life, 7(4), 337-350. doi:10. 1007/s11482-012-9167-9

Yoon, E., Chang, C.-T., Kim, S., Clawson, A., Cleary, S. E., Hansen, M., ... Gomes, A. M. (2013). A metaanalysis of acculturation/enculturation and mental health. Journal of Counseling Psychology, 60(1), 15-30. doi:10.1037/a0030652

Zell, E., \& Alicke, M. D. (2009). Contextual neglect, self-evaluation, and the frog-pond effect. Journal of Personality and Social Psychology, 97(3), 467-482. doi:10.1037/a0015453 
Appendix 1. The Feelings At School Scale (FASS). Positive Affect subscale: Items 1, 3, 5, and 7. Negative Affect subscale: Items 2, 4, 6, and 8

\begin{tabular}{|c|c|c|c|c|c|}
\hline $\begin{array}{l}\text { If you think about how you felt at school over the past few } \\
\text { months, how often did you experience the following feelings? } \\
\text { Put a cross in only one box for each question }\end{array}$ & Never & Rarely & Sometimes & Often & $\begin{array}{l}\text { Very } \\
\text { often }\end{array}$ \\
\hline 1. I felt happy & $\square_{1}$ & $\square_{2}$ & $\square_{3}$ & $\square_{4}$ & $\square_{5}$ \\
\hline 2. I felt sad & $\square_{1}$ & $\square_{2}$ & $\square 3$ & $\square 4$ & $\square_{5}$ \\
\hline 3. I felt cheerful & $\square_{1}$ & $\square_{2}$ & $\square_{3}$ & $\square_{4}$ & $\square_{5}$ \\
\hline 4. I felt upset & $\square_{1}$ & $\square_{2}$ & $\square_{3}$ & $\square_{4}$ & $\square_{5}$ \\
\hline 5. I felt good & $\square_{1}$ & $\square_{2}$ & $\square_{3}$ & $\square_{4}$ & $\square_{5}$ \\
\hline 6. I felt worried & $\square_{1}$ & 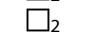 & $\square$ प & & \\
\hline 7. I felt calm & $\square$ & $\square_{2}$ & $\square_{3}$ & $\square_{4}$ & ப \\
\hline 8. I felt angry & $\square_{1}$ & $\square_{2}$ & $\square_{3}$ & $\square_{4}$ & 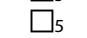 \\
\hline
\end{tabular}

